\title{
Simulation and Techno-Economic Performance of a Novel Charge Calculation and Melt Optimization Planning Model for Steel Making
}

\author{
Onigbajumo Adetunji ${ }^{*}$, Saliu 0jo Seidu² \\ ${ }^{1}$ School of Mechanical, Medical and Process Engineering, Queensland University of Technology, Brisbane, Australia \\ ${ }^{2}$ Department of Metallurgical and Materials Engineering, Federal University of Technology, Akure, Ondo State, Nigeria \\ Email: *a.onigbajumo@qut.edu.au
}

How to cite this paper: Adetunji, O. and Seidu, S.O. (2020) Simulation and Techno-Economic Performance of a Novel Charge Calculation and Melt Optimization Planning Model for Steel Making. Journal of Minerals and Materials Characterization and Engineering, 8, 277-300.

https://doi.org/10.4236/jmmce.2020.84017

Received: June 4, 2020

Accepted: July 27, 2020

Published: July 30, 2020

Copyright $\odot 2020$ by author(s) and Scientific Research Publishing Inc. This work is licensed under the Creative Commons Attribution International License (CC BY 4.0).

http://creativecommons.org/licenses/by/4.0/

(c) (i) Open Access

\begin{abstract}
Process algorithm, numerical model and techno-economic assessment of charge calculation and furnace bath optimization for target alloy for induction furnace-based steelmaking is presented in this study. The developed algorithm combines the make-to-order (MTO) and charge optimization planning (COP) of the steel melting shop in the production of target steel composition. Using a system-level approach, the unit operations involved in the melting process were analyzed with the purpose of initial charge calculation, prevailing alloy charge prediction and optimizing the sequence of melt chemistry modification. The model performance was established using real-time production data from a cast iron-based foundry with a 1- and 2-ton induction furnace capacity and a medium carbon-based foundry with a 10- and 15-ton induction furnace capacity. A simulation engine (CastMELT) was developed in Java IDE with a MySQL database for continuous interaction with changing process parameters to run the model for validation. The comparison between the model prediction and production results was analyzed for charge prediction, melt modification and ferroalloy optimization and possible cost savings. The model performance for elemental charge prediction and calculation purpose with respect to the charge input (at overall scrap meltdown) gave R-squared, Standard Error, Pearson correlation and Significance value of $(0.934,0.06,0.97,0.0003)$ for Carbon prediction, $(0.962,0.06,0.98,0.00009)$ for Silicon prediction, $(0.999,0.048,0.999,9 \mathrm{E}-11)$ for Manganese Prediction, and $(0.997,0.076,0.999,6 \mathrm{E}-7)$ for Chromium prediction respectively. Correlation analysis for melt modification (after charging of ferroalloy) using the model for after-alloying spark analysis compared with the target chemistry is at $99.82 \%$. The results validate the suitability of the developed model as a functional system of induction furnace melting for combined charge calcula-
\end{abstract}


tion and melt optimization Techno-economic evaluation results showed that $0.98 \%-0.25 \%$ ferroalloy saving per ton of melt is possible using the model. This brings about an annual production cost savings of $100,000 \$ / y$ in foundry A (medium carbon steel) and 20,000 \$/y in foundry B (cast iron) on the use of different ferroalloy materials.

\section{Keywords}

Charge Calculation, Process Simulation, Modelling, Induction Furnace, Steel Making, Techno-Economics, Mass and Energy Balance

\section{Introduction}

Melting as a major operation in the foundry is carried out by charging commercially pure metals, external and internal scrap, and additives to achieve a target alloy composition. The process includes melting the charge, refining the melt, adjusting the melt chemistry and tapping into the transport vessel [1] [2]. Refining is done to remove the deleterious gases and elements from the molten metal through material addition to bring the final tap chemistry within a specific range set by internal standard and/or industry [3]. Cast Iron and Steel scraps are the most important raw material in the foundry shop where cast products of the scrap melts are produced contributing about $60 \%$ to $80 \%$ of the total production costs [4] [5]. Cast products ranging from simple machine parts to special steel alloys are produced from an intelligent campaign in the foundry shop through programming intelligence [6]. In recent times, the extent to which the scrap mix for refining can be optimized, and the degree to which the melting operation can be controlled and automated to achieve the right chemistry of melt in the foundry is limited by the knowledge of the properties of the scrap and other raw materials in the charge mix [7] [8] [9].

It is noteworthy that charge calculation for foundry operation could be very cumbersome ranging from several hours to days [10] [11]. The quality of the steel produced from the EAF, crucible, or induction furnace largely depends on the charge mix, quality of scrap and additives [9] [12]. Static models are based on materials and heat balance by considering initial and final states of reactants. In the material balance, mass of all input and output elements are considered alongside heat balance [6] [13] [14]. By coupling of mass balance, one can predict; the quantity of hot metal and scrap, amount of flux, the total quantity of oxygen required to be blown, amount of slag produced, the volume of exit gases, amount of ferro-additives [11] [15] [16]. It is however very much important that the prediction based upon the model is verified by the actual plant data. Tuning of the model is necessary because the predictions are based on equilibrium considerations and uncertainties due to simplified assumptions [17]. Reliability of predictions increases when the predictions of the model are compared with the plant data for several heats [18] [19]. Statistical correlations can then be eva- 
luated and used to assess the reliability of the model. For this purpose, it is of utmost necessity to collect reliable data from the high-precision instrument.

Induction and crucible furnace using a system-level approach can be analyzed for stochastic modelling [6]. A possible error in predictions makes a static model almost inadequate for intelligence control and automation of charge [12]. In a programmed model, these values are fed continuously, and corrections can be done during the melting operation. It becomes extremely difficult by foundry managers to combine the demand for a target quality through charge dynamics with energy and least cost operatives [20] [21]. The constraint with the induction furnace system with which the formation of oxides and decarburization through oxygen blowing is not permissible makes it very challenging for foundrymen to utilize it for alloy requiring close range compositions [22] [23] [24] [25] [26]. However, this area has received very little research attention. To the best of the author's knowledge, there is no research attempting a detailed numerical model for system-level material optimization and charge planning of induction furnace melting aimed at operational cost savings in steelmaking. Consequently, this work considers the parameters of the system-level and operations of the induction furnace to develop main and sub-models related to the stages involved in scrap charge and melting. Sub-equations relating to initial scrap analysis, bath chemistry of the initial melt, heel melting factor, mass density, scrap chemistry, ferroalloy composition, and final alloy target which cannot be obtained once melt modification begins due to the nature of the process are obtained on a theoretical basis. Through detailed modelling of the system-level parameters required for induction furnace melting of scrap, this study presents a parametric and validation study to understand the charge balancing, furnace bath melt optimization, and ferroalloys savings possible with induction furnace melting.

\section{Materials and Method}

The numerical model is developed using the principle of materials balance and system-level analysis. The system-level approach involves the analysis of a large system as a unit without analytical consideration of the lower-level subsystems. This approach provides the requirements on systems and application program design in the form of explicit models of system behavior and defines the state-based architecture of the control system. The process algorithm, which was developed with the understanding of the operation sequence of induction furnace steel melting is presented in Figure 1. The model framework assumes a steady-state metallurgical system in the melting of scrap using the induction furnace with equal electromagnetic induction energy incident upon all charged materials.

\subsection{Modelling}

The mode of production in the modern manufacturing enterprise is mainly referred to as MTO (Make-to-Order). However, to reasonably rearrange the production plan 


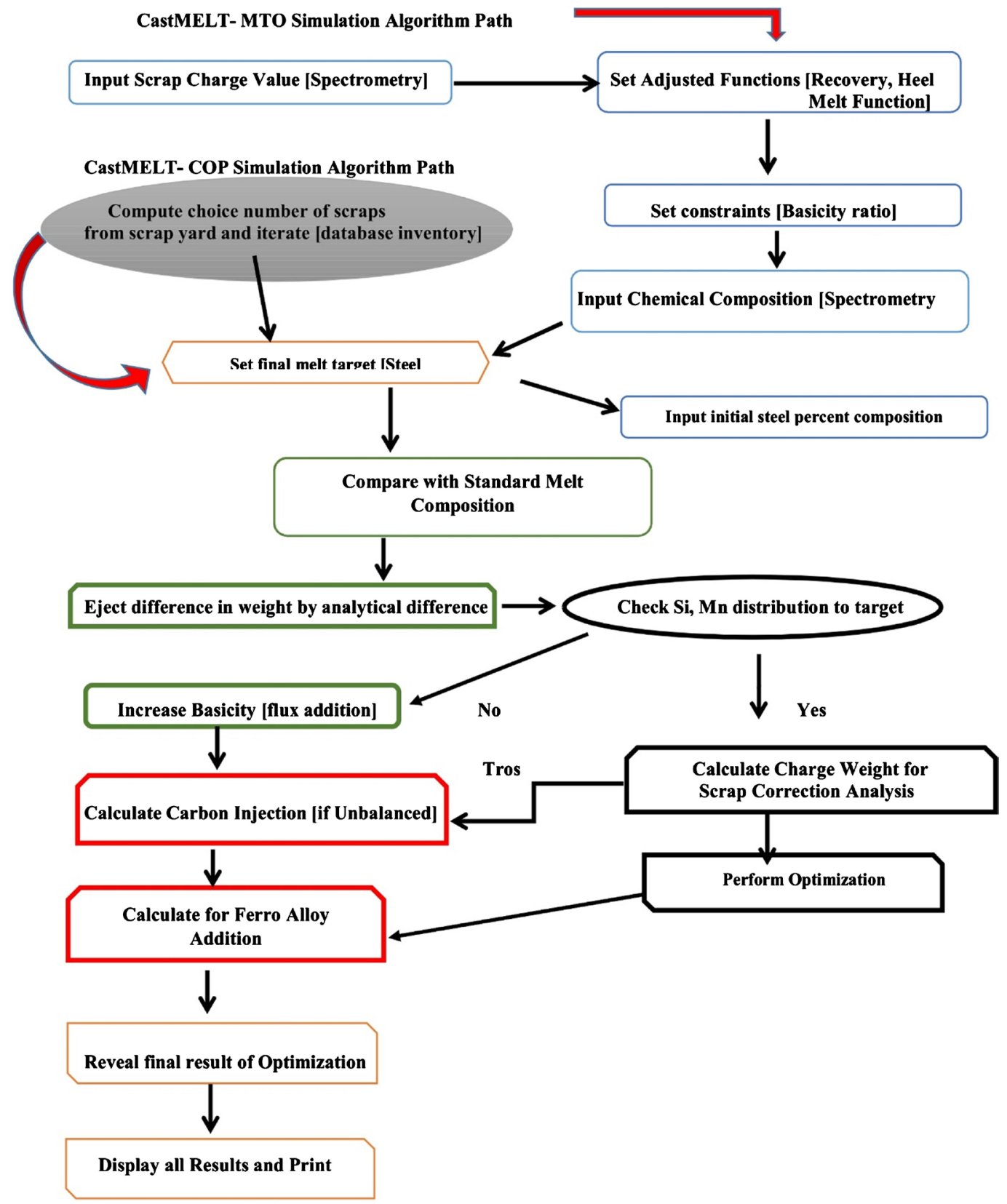

Figure 1. Process Simulation Algorithm for Material Optimization (MTO-Make-To-Order, COPCharge Optimization Planning).

to consumer target and standard is a very arduous and common problem for foundry managers amidst improving their inner production reformation in the competitive market environment. This will be handled by a charge analysis and fitness model. The material system model for the induction and crucible furnace is based on the principle of mass balance. The induction furnace operation for charging sequence and melt modification is assumed to be a closed system function in relation to the law of conservation of mass [6] [11].

The general form for an open system is given by:

Mass input $=$ Mass output + Net Accumulation within the system 


$$
\text { Total Mass balance }=\sum_{j=1}^{m} f_{i j} F_{i}-\sum_{j=1}^{k} p_{i j} P_{j}=0
$$

where $\left(F_{i}, P_{i}\right)$ are masses and $\left(f_{i p}, p_{i j}\right)$ are analysis or content.

\subsubsection{Composition Charge Analysis Model}

In the case of an industrial melting operation, where a large amount of assorted/ aggregate scraps are charged into the furnace, the simulation program algorithm recognizes such as online-real time unit operation path. Taking cognizance of the initial melting operation, the operational recovery lead to the retention of molten metal in the working region of the furnace.

The Heel Melting Factor (HMF) is observed in the empirical analysis (actual state analysis) as:

$$
\begin{gathered}
\text { hmf }=[\text { i-Melt } * 1.11] *(100-R) / R \\
\text { hmf }=[\mathrm{i}-\operatorname{Scrap} *(100-R)] / R
\end{gathered}
$$

- Where hmf is the heel factor intended to predict the amount of molten metal retained in the working portion of the furnace.

- i-Melt is the amount of molten steel that was successfully tapped from the previous melt.

- i-Scrap is the amount of scrap charged in the previous melting operation.

- and $R$ is the operational recovery of the steel melting shop.

In the case of a specialized melting, experimental melting plan and prescribed or on-request melt batch, the simulation program algorithm follows an offline patch with pseudo melting analysis with the artificial intelligence pathway of the furnace.

\subsubsection{Scrap Charge Model}

For a n-list of scrap charge with each scrap having an already known or recorded chemical analysis, the overall amount of scrap charge is defined in Equation (4):

$$
\mathrm{j}-\mathrm{Scrap}=M_{a}+M_{b}+M_{c}+M_{d}+\cdots+M_{n}
$$

where $M$ is the mass of the individual scrap $a, b, c, d, \cdots, n$.

$\mathrm{j}$-Scrap is the overall amount of all the scrap charge in $\mathrm{Kg}$.

The overall percentage composition of an element $(x)$ in the scrap $a, b, c, d, \cdots, n$, is defined with Equation (5):

$$
x_{n}=0.01 R * \mathrm{j}-\mathrm{S} \operatorname{Scrap} \sum_{a}^{n} x_{i} \cdot M
$$

where $X_{n}=$ the new $\%$ composition of an element $(x)$ upon the overall addition of the scrap.

Individual melt analysis in $\mathrm{kg}$ of individual element in each scrap is defined by Equation (6)

$$
x(\text { in } \mathrm{kg})=0.01 *\left[x_{i} * \mathrm{j}-\mathrm{Scrap}\right]
$$

Elemental difference between the bath analysis and the target standard composition is defined by the function in Equation (7) 


$$
0.01 * \mathrm{j}-\operatorname{Scrap}\left[x_{s t}-x_{n}\right]
$$

- Where $x_{s t}$ is \% composition of element $(x)$ in the target standard melt.

- $x_{n}$ is \% composition of the element $(x)$ in the bath analysis.

\subsubsection{Flux Addition Model}

The estimation for the addition of flux is a function of the operational recovery of the melting shop which defines the amount of molten metal that did not report to tapping operation. The amount of flux (quicklime or dolomite) to be added to the melt is defined in Equation (8):

$$
\text { Mass of Flux }=[0.01(100-R) * \mathrm{j}-\mathrm{Scrap}] * \% \mathrm{CaO} / \mathrm{MgO} \text {. }
$$

\subsubsection{Scrap-Bath Analysis Correction}

The use of scrap to correct the chemistry of the melt is a known practice in induction steel melting. This precludes the reason why efficient scrap sorting, classification, and selection is very inevitable in the foundry especially with the use of induction and crucible furnace melting.

When the bath analysis of the current melting is obtained from the spectrometric analysis, the data therein is used to determine the amount of scrap that will be required to change the bath analysis to the intended chemistry bearing in mind a particular element type. The mass of scrap to be injected into the current bath for chemistry adjustment is defined by the model in Equation (9):

$$
M_{i n j}=R^{i}\left|\left[\mathrm{j}-\operatorname{Scrap} * \frac{\left(x_{n}-x_{s t}\right)}{\left(x_{s t}-x_{s c}\right)}\right]\right|
$$

- Where || is an absolute value operator.

- $M_{i n j}$ is Mass of the injected/incoming scrap.

- $X_{s c}$ is \& composition of element $(x)$ in the incoming scrap.

- $R^{i}$ is Elemental Recovery of the injected scrap.

The new \% composition of each element in the bath analysis after the injection of the new scrap is defined in Equation (10):

$$
x_{\text {bath }}=\left[\frac{\left(x_{n} * \mathrm{j}-\mathrm{Scrap}\right)+\left(x_{s c} * M_{i n j}\right)}{\left(\mathrm{j} \text {-Scrap }+M_{i n j}\right)}\right]
$$

- where $x_{\text {bath }}$ is the \% composition of element $(x)$ after the injection of scrap.

- $x_{n}=\%$ composition of element $(x)$ in the melt before the injection.

\subsubsection{Ferro Alloy and Additives Addition}

Ferroalloy addition (FeMn, SiMn) or other additives (graphite or mill scale) depending on the bath analysis after the initial scrap meltdown could be done before or after melt correction in the furnace. Depending on the type of major element that is a shortfall of the target composition, the ferroalloy is added. Most times scrap addition for chemistry adjustment is preferable for cost savings. This is because the cost of ferroalloys is expensive compared to the cost of scrap. This pathway, however, makes modelling a veritable tool for melt optimization and 
cost savings in the foundry.

Ferro alloy (additive) addition is defined by the function in Equation (11):

$$
M_{f a}=\left|\mathrm{j}-\operatorname{Scrap}\left(x_{n}-x_{s t}\right) /\left(x_{s t}-x_{f a} * R^{i}\right)\right|
$$

- where $x_{f a}$ is the \% composition of the target element in the ferroalloy/additive to be added.

- $M_{f a}$ is the mass of ferro alloy to be added to the bath.

- $R^{i}$ is the elemental recovery of the element added from the ferro alloy/additives.

- Other symbols have their usual meaning.

Effect of the addition of ferroalloy/additives in the bath analysis is defined in Equation (12):

$$
x_{b a t h}=\left[\frac{\left(x_{n} * \mathrm{j}-\mathrm{Scrap}\right)+\left(x_{f a} * M_{f a}\right)}{\left(\mathrm{j}-\mathrm{Scrap}+M_{f a}\right)}\right]
$$

- where $x_{f a}$ and $M_{f a}$ is the \% composition of the intended element in the ferroalloy/additive and mass in $\mathrm{kg}$ of the ferroalloy added respectively.

Upon the addition of more ferroalloys/additives or scrap, depending, the j-scrap becomes incremental with the addition of new weight of charges. For instance, the weight of the melt upon an initial scrap addition/ferro alloy/additives is defined by:

$$
\mathrm{j} \text {-Scrap new }=\left(\mathrm{j} \text {-Scrap }+\frac{M_{f a}}{M_{s c}}\right)
$$

The new j-Scrap value is erstwhile used in the next calculation for bath analysis correction.

\subsection{Scrap Charge Optimization}

The simulation program algorithm defines a pathway in the overall model which creates the possibility for the user to perform a pseudo melting operation right from the computer without the real-time, physical operation of the furnace. This is intended to utilize the advantage of a neural network and mathematical iteration to create a pathway in which the simulation program mimics the melting environment of the furnace with the usability of a database of scrap inventory developed into this current algorithm as compared to that available in Seidu and Onigbajumo, 2015 [6].

The iteration continues in the form:

$$
x_{i}^{(k+1)}=\frac{1}{a_{i}}\left(b_{i}-\sum_{j \neq i} a_{i j} x_{j}^{(k)}\right), i=1,2, \cdots, n
$$

This implies that Equations ((4)-(6), (9) and (10)) is returned for $n$ number of times in the general Gauss-Seidel iteration function in Equation (14) until the set value is approximately attained.

Resultant \% composition of any element type (say $x$ ) when additional scrap is added and repeated until the target composition is attained using iteration is ex- 
pressed in Equation (15):

$$
\% x^{0}=x_{i}^{(k+1)} \frac{\left(M_{s t} \times x^{i}\right)+\left(M_{s c} \times x^{n} \times R^{o}\right)}{\left(M_{s t}+M_{s c}\right) \times 100 \%}
$$

$x^{0}$ is the resultant composition of an element $(x)$ upon new additions of scrap/ferro-alloy.

Ferro-alloy addition containing an element $(x)$ is added according to Equation (16),

$$
\% x^{0}=\frac{\left(R^{i} \cdot M_{s t} \times x^{i}\right)+\left(M_{f a} \times x^{m} \times R^{o}\right)}{\left(M_{s t}+M_{f a}\right) \times 100 \%}
$$

When two additions were made i.e. ( $\mathrm{i}$ and ii), the overall resultant composition will be an iteration of Equation (16)

$$
\% x^{0}=x_{i}^{(k+1)} \frac{\left(R^{i} \cdot M_{s t} \times x^{i}\right)+\left(M_{s c} \times x^{n} \times R^{o}\right)+\left(M_{f a} \times x^{m} \times R^{o}\right)}{\left(M_{s t}+M_{f a}+M_{s c}\right) \times 100 \%}
$$

We can deduce the mass of scrap to be added to achieve the expected target composition by re-arranging Equation (15), therefore,

$$
M_{s c}=\frac{M_{s t}\left(x^{i} R^{i}-x^{o}\right)}{\left(x^{o}-x^{n} R^{o}\right)}
$$

where $M_{s c}$ represents the mass of scrap that must be added.

Re-arranging Equation (17), we can calculate the mass of ferroalloy/additive to charge upon scrap upon an earlier correction.

$$
M_{f a}=\frac{M_{s t}\left(R^{i} x^{i}-x^{o}\right)+M_{s c}\left(x^{n}+R^{o}-x^{o}\right)}{\left(x^{o}-x^{m} R^{o}\right)}
$$

where $M_{f a}$ represents the mass of scrap that must be added.

The implementation of the off-schedule Pseudo Melting algorithm brings in a lot of flexibility and allows user control and planning to offset material stock (for Charge Optimization Planning-COP). With the implementation of the iteration cycle, several charge continuums are possible with the furnace manager deciding the amount of material charge and new melt composition is implemented instantaneously based on the charge.

\subsection{Experimental Set-Up}

The charge optimization, melt modification, and ferroalloy addition models developed in this study to achieve target melt composition was established by testing against real-time operational data in two different commercial foundry plants. Plant A is a low-alloy medium carbon steelmaking foundry with 10- and 15-tons induction furnace and plant B produces high-alloy cast-iron products (high manganese, high chromium) with 1- and 2-ton induction furnace system. Four melts were obtained with foundry A and six melts achieved in foundry B in a total of 6 production days using aggregate scrap at plant A and known scrap 
composition at plant B. Real time simulation using the same operational data of both foundry shops were performed using the developed model through a computational simulation program engine (CastMELT), written in Java and MYSQL database server to run the numerical models. The relationship between predicted data and real-time melting shop experiments were analysed using statistical tools in MS Excel.

In order to ascertain the compatibility of the developed model as well as its adaptation to industrial usage, real time operation data were obtained from an industrial plant with custom casting foundry operation. The analysis large scale commercial structural steel production analysis. The statistical validation analysis employed in the validation include-Regression Analysis, ANOVA, Pair-T Test, Pearson's Correlation, and Scatter Plot Analysis Correlation using the Microsoft Excel Tool.

The following evaluations and validity were made to confirm the suitability of the model using the simulation engine:

i) Charge Analysis Prediction: this is for verification of the model in predicting values as obtainable during the melting operation of the plants visited.

ii) Melt Modification, Correction Function and Optimization Analysis: this is to subject the simulation engine (CastMELT) to melt correction function and analysis to verify its melt correction and material optimization functionality.

\subsection{Cost Savings Methods}

Standard product quality vis-à-vis production cost management is key to the continuous operation of iron and steel plants. Large amount of production loss is incurred in the foundry through poor material sorting and selection, inaccurate material charging, excess energy consumption due to wrong materials charge, time loss due to melt correction. Foundry engineers, production manager and relevant stakeholders of a foundry plant are continuously seeking approaches to cost savings without bringing down the integrity of their cast products. Cost saving is achievable through:

1) Efficient material accounting and scrap sourcing.

2) Charge calculation and materials balancing.

3) Melt modification and optimization.

4) Energy management and heat recovery.

5) Production time management with the utilization of steel melting and casting software.

\section{Results and Discussion}

The real-time operational data for both foundries include the information on the scrap mix (steel, cast iron, and foundry returns), ferro additive type (mill scale, medium carbon $\mathrm{FeMn}$, high carbon $\mathrm{FeMn}, \mathrm{FeCr}$, and $\mathrm{FeSi}$ ), the weight of scrap and ferro-alloy charge, tapping temperature, cycle time (tap to tap time which includes all time losses). The operational or production data also includes the 
furnace used and the furnace power rating which determines the melting rate as presented in supplementary material 1 and 2. The developed simulation engine (CastMELT) was used to adapt this operational data and simulate the process outcome based on the models developed in the previous section. The numerical model was evaluated first for charge calculation predictions using the simulation engine with the results presented in supplementary material 3 and 4 for foundry A (medium carbon steel) and foundry B (cast iron) respectively. This is to verify the use of the numerical model in giving close output for charge balance using the same operation data for both foundries when loaded in the simulation engine database.

\subsection{Comparison between Model Prediction and Production Results}

Figures 2-5 show the relationship between the melt composition for carbon, silicon, manganese, and chromium for foundry A for four (4) heats and Figures 6-9 show the same element relationship for foundry B for six (6) heats as a basis for statistical correlation analysis. Pearson's correlation coefficient results show $81 \%$ to $95.7 \%$ and $0.12-0.47$ respectively for foundry A and B, respectively. Standard error stands at $0.12-0.47$ for foundry A and $0.005-0.089$ for foundry

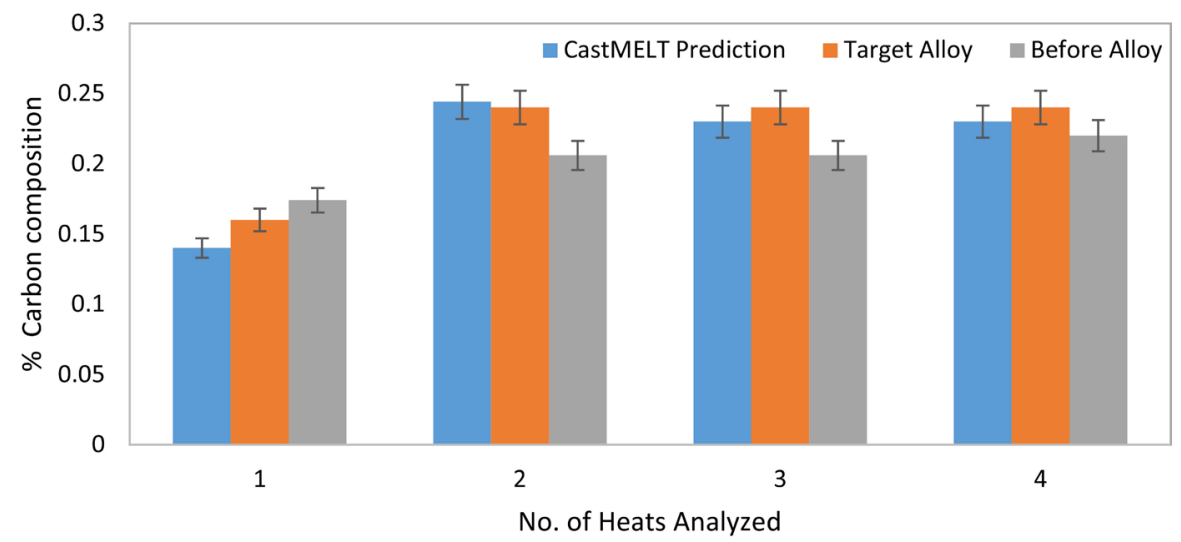

Figure 2. Correlation Scatter Plot comparing Spectrometric Analysis (SMC) after alloy addition with CastMELT for Carbon composition (SMC).

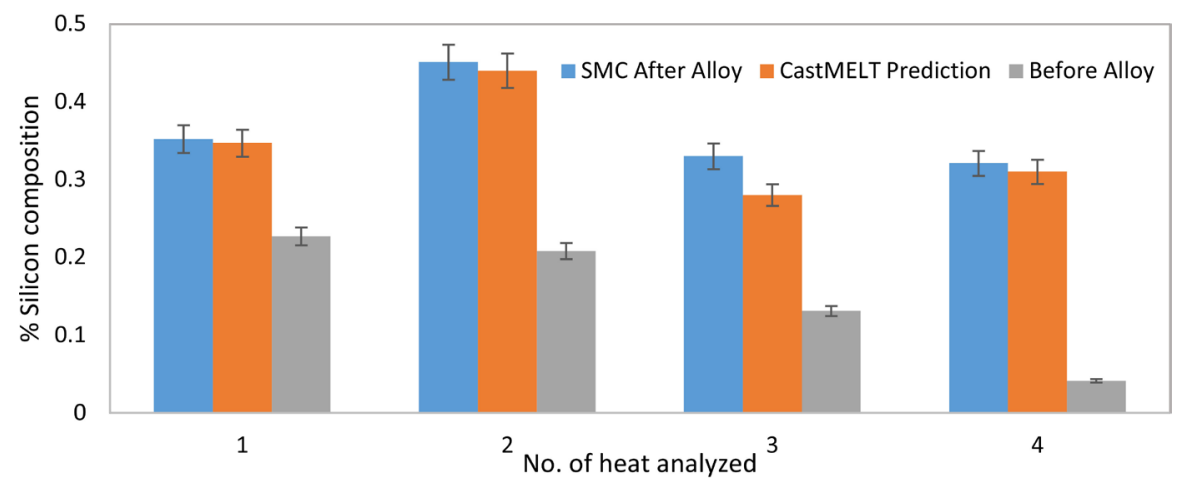

Figure 3. Correlation Scatter Plot comparing Spectrometric Analysis (SMC) after alloy addition with CastMELT for Silicon composition (SMC). 


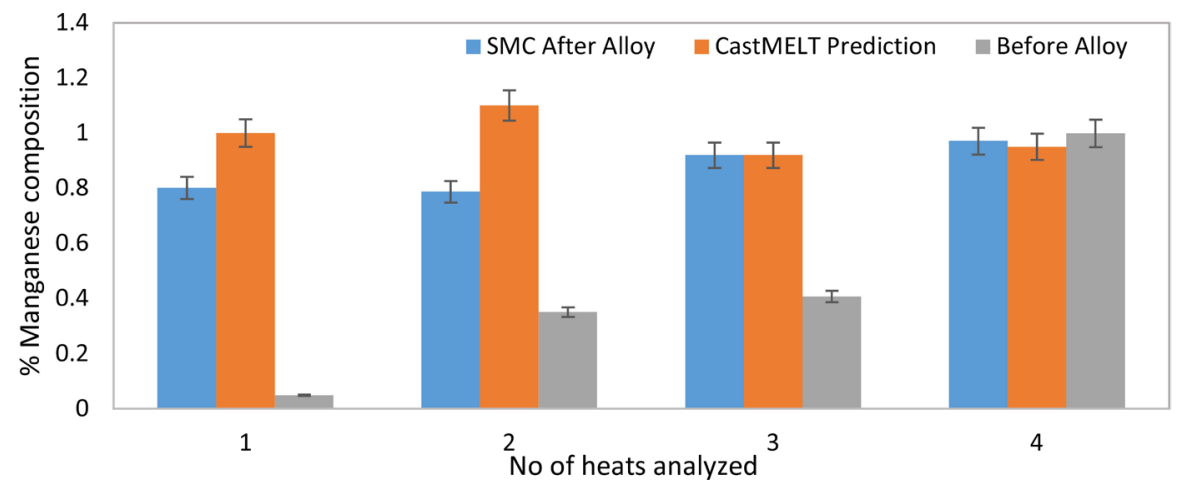

Figure 4. Correlation Scatter Plot comparing Spectrometric Analysis (SMC) after alloy addition with CastMELT for Manganese composition (SMC).

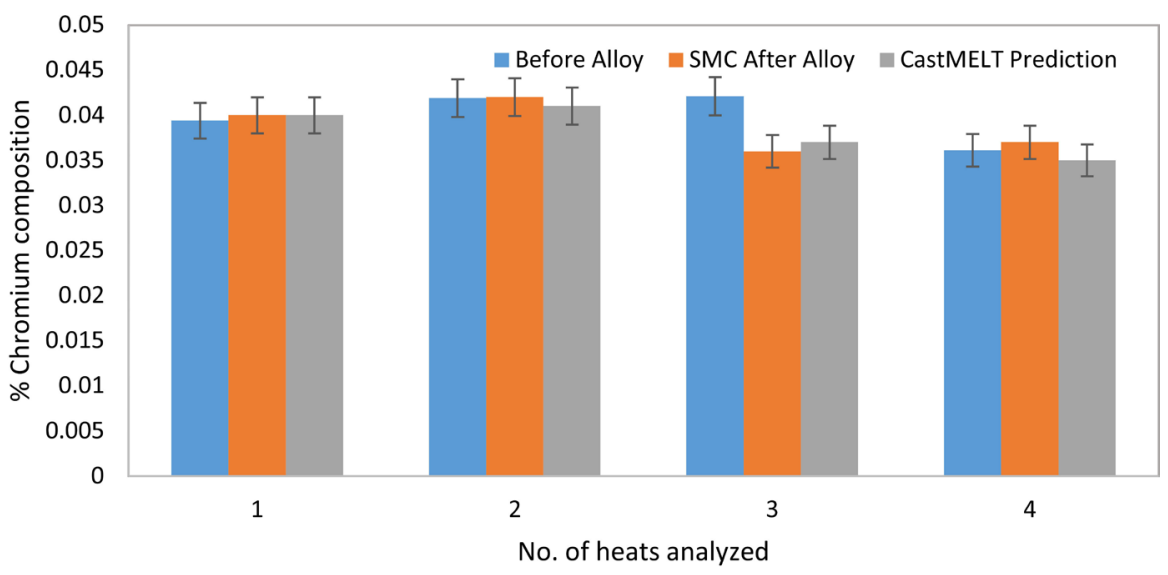

Figure 5. Correlation Scatter Plot comparing Spectrometric Analysis (SMC) after alloy addition with CastMELT for Sulphur composition (SMC).

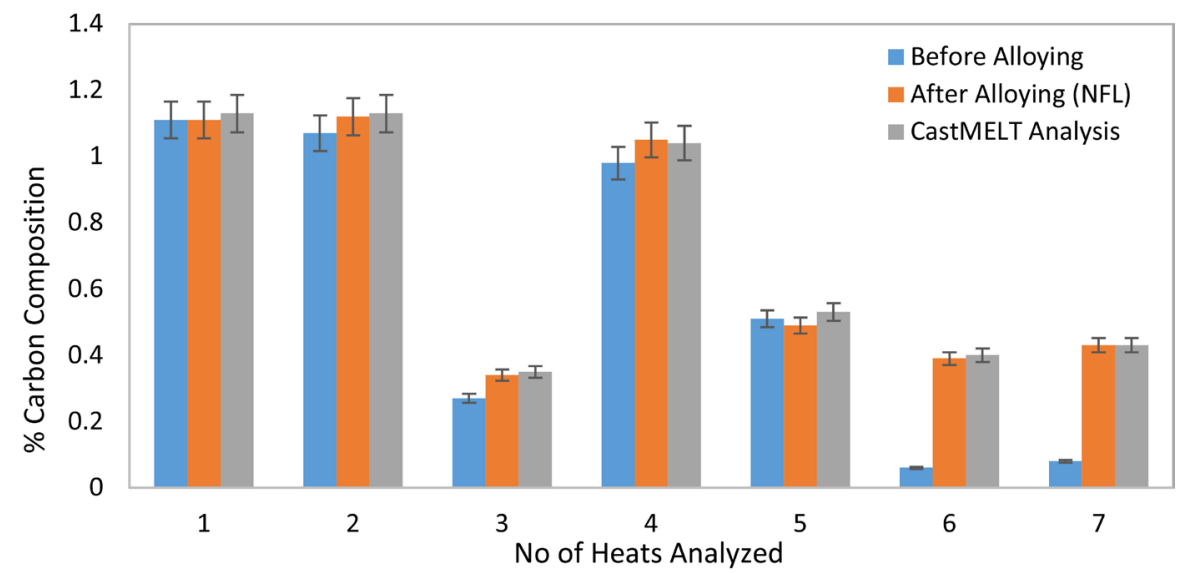

Figure 6. Correlation Scatter Plot Comparing Spectrometric Analysis (NFL) after Alloy Addition with CastMELT for Carbon composition.

B. The high correlation in foundry B plant is largely due to the use of known scraps as compared to foundry A with the use of aggregate scrap. Foundry A also has a basic oxygen furnace where the steel melt is further treated especially when the amount of carbon which is very challenging to control in the induction furnace. This makes the overall melting activities to proceed in on-site with less 


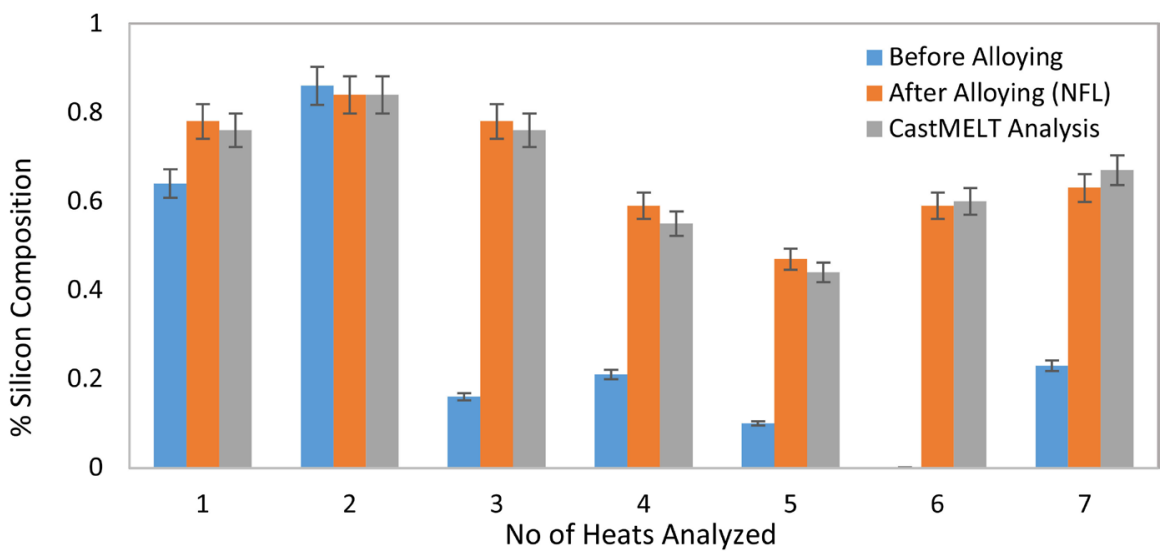

Figure 7. Correlation scatter plot comparing spectrometric analysis (NFL) after Alloy Addition with CastMELT for silicon composition.

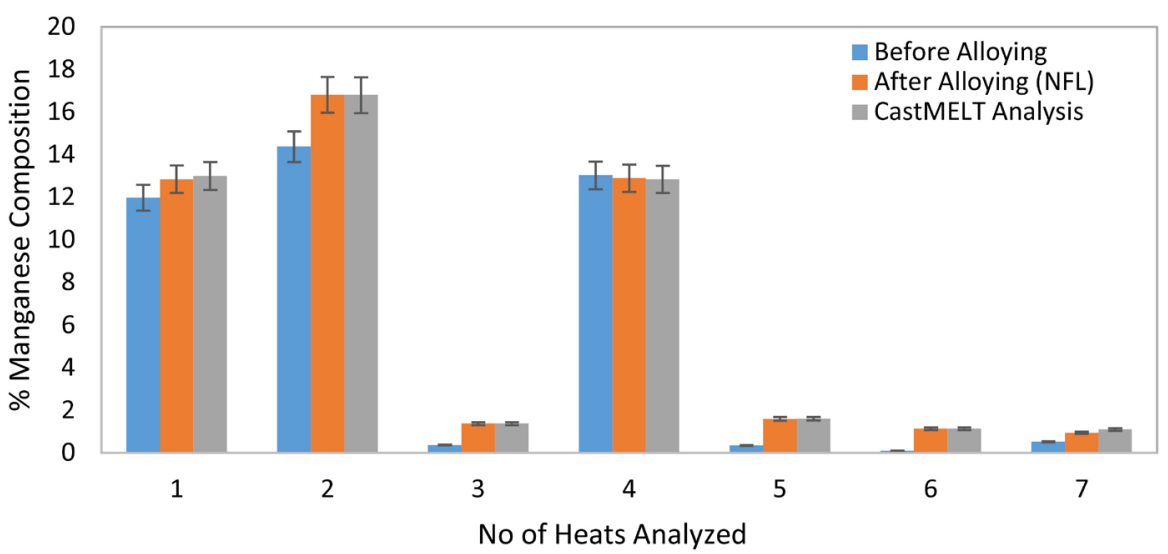

Figure 8. Correlation scatter plot comparing spectrometric analysis (NFL) after Alloy Addition with CastMELT for Manganese composition.

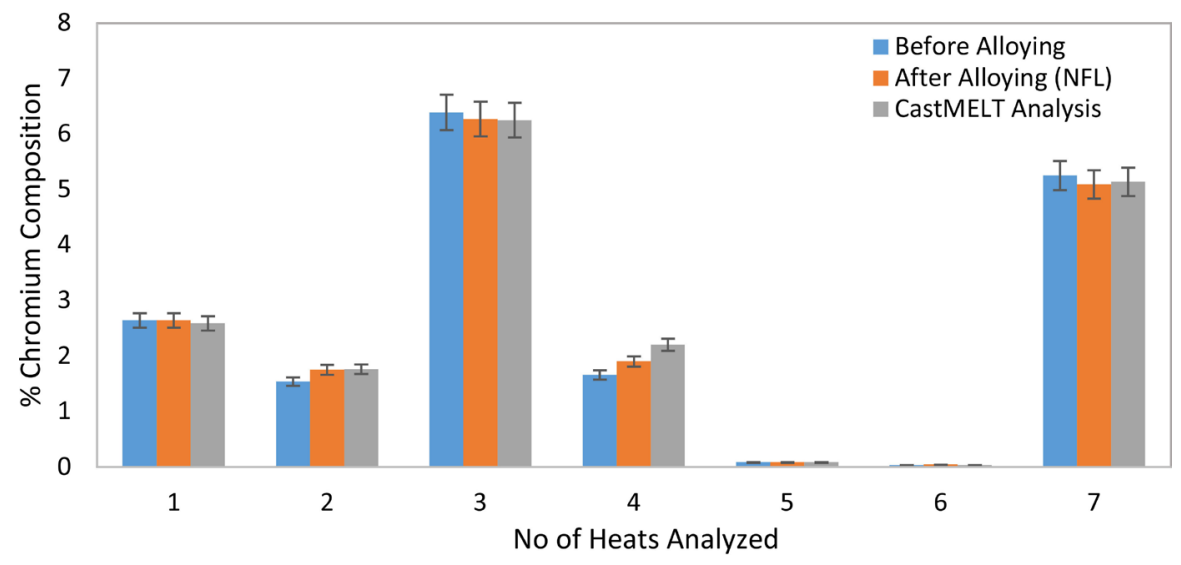

Figure 9. Correlation Scatter Plot Comparing Spectrometric Analysis (NFL) after Alloy Addition with CastMELT for Chromium composition.

control compared to foundry A. Elemental compositions for charge calculation and material balance had the highest Pearson's correlation for silicon and carbon at $96 \%$ and $90.7 \%$ respectively for foundry A melting practice. Carbon and manganese had the highest correlation at $99 \%$ each for charge calculation and 
material balance in foundry B based on the melting practice.

\subsection{Melt Modification and Ferroalloy Optimization}

The numerical model using the simulation engine was also evaluated for melt treatment and modification using scrap and ferroalloy addition to achieve target melt composition. A comparison was made between the final melt composition, CastMELT simulation engine final melt prediction, and the target chemistry of the produced cast in both foundries. The simulation was done using the same real-time production data for the period of this evaluation. The results are presented in Figure 10 for foundry A for four (4) melts and Figure 11 for foundry B for six (6) melts. The target melt composition is set at the upper bound value of the major elements considered (carbon, silicon, manganese, and chromium) in order to assess the extent to which the results from the model and outcome of real-time melting and alloying at both foundries are close with the target composition.

From the results are shown in Figure 10 and Figure 11, foundry A shows a convergence $91.05 \%$ of the final alloy (after alloy as shown in the graph) within the target composition range of the melt. The model developed in this study, however, reports $97.87 \%$ overall prediction convergence for foundry A with the four-melting experiments. After-alloy convergence for foundry B results in higher confidence of $97.82 \%$ while the model (using the simulation engine) reports

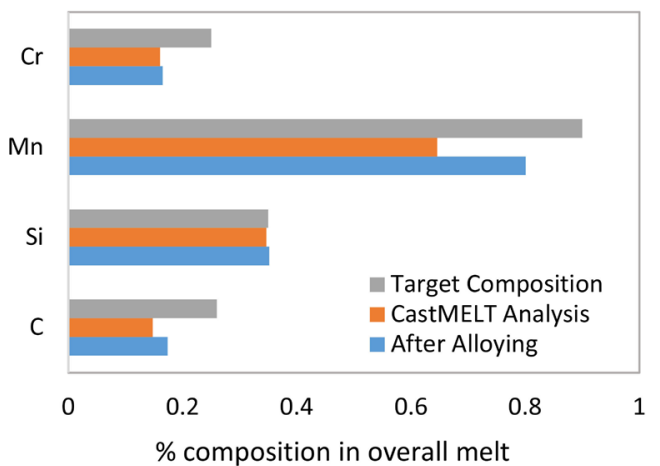

(a)

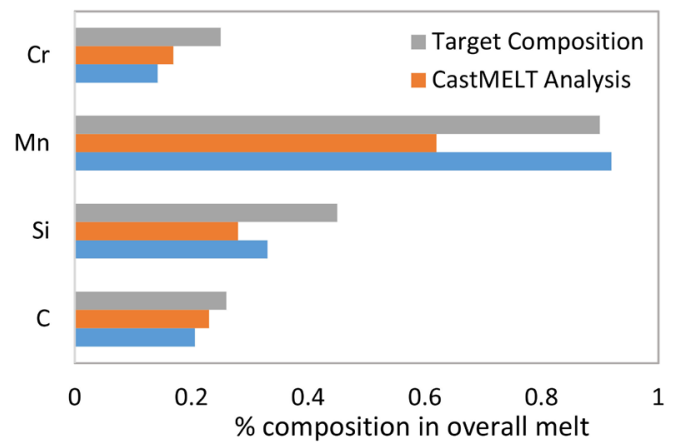

(c)

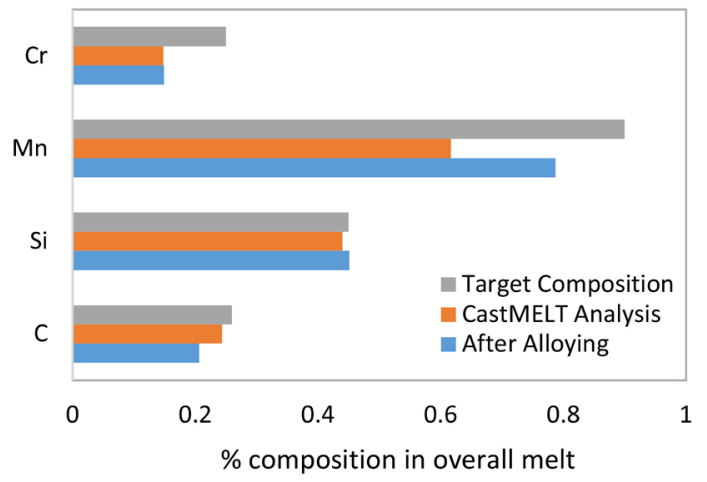

(b)

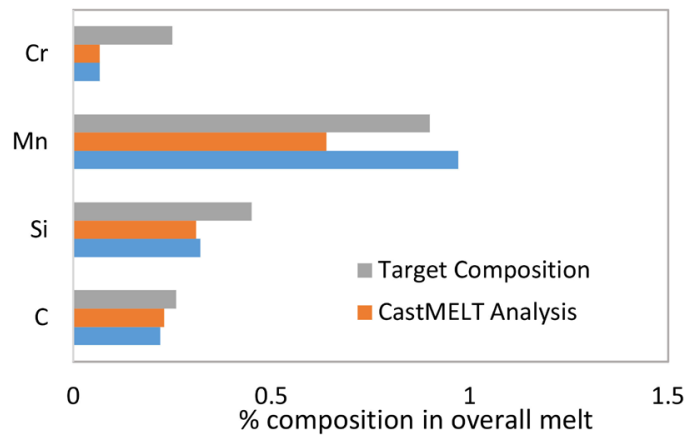

(d)

Figure 10. Comparison between after alloy (real time SMS operation), model (CastMELT simulation engine) and target chemical composition of four melting operation in foundry A for four (4) melts. 


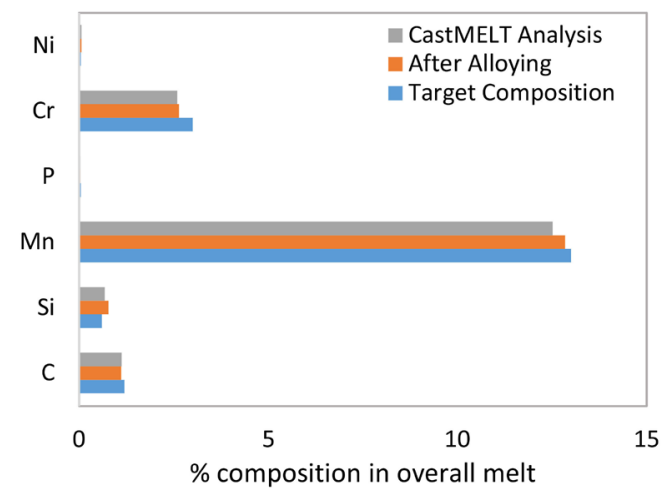

(a)

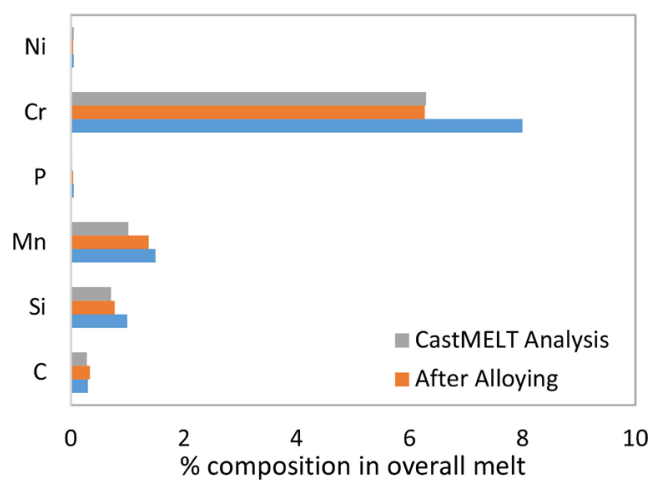

(c)

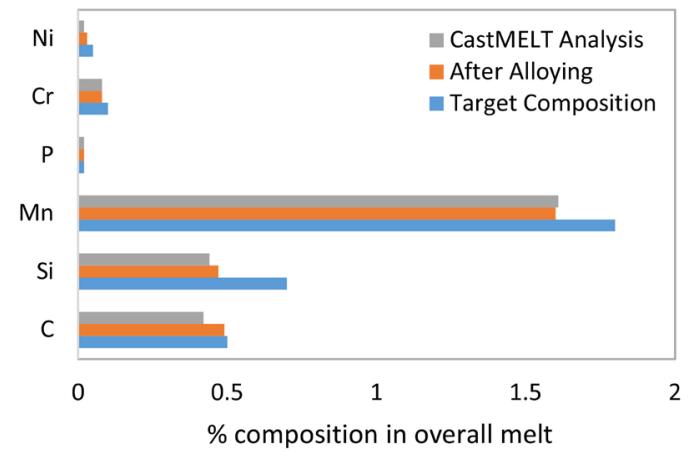

(e)

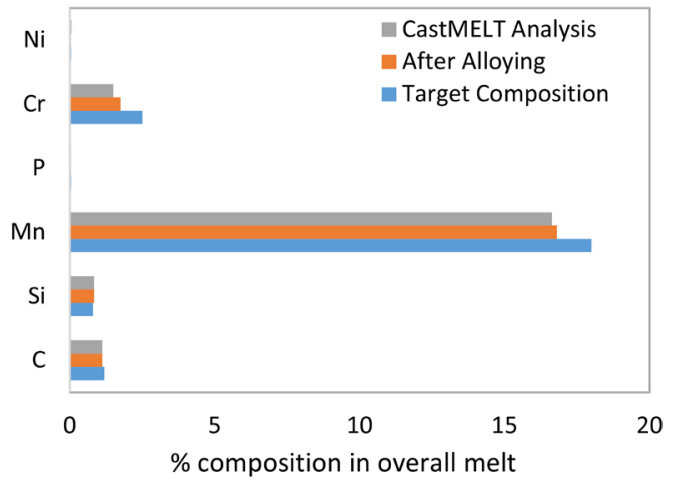

(b)

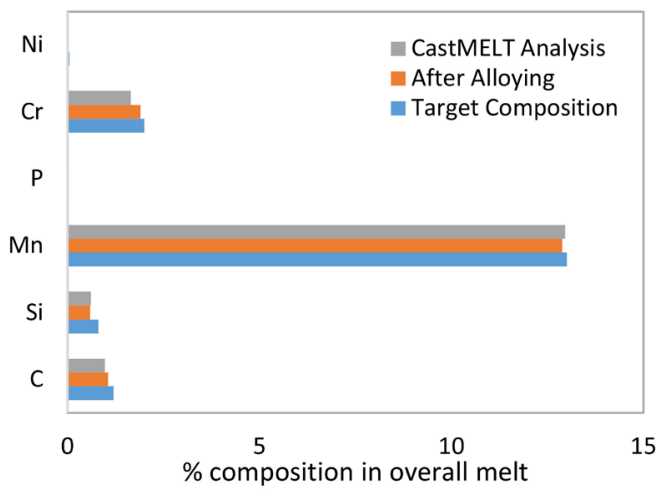

(d)

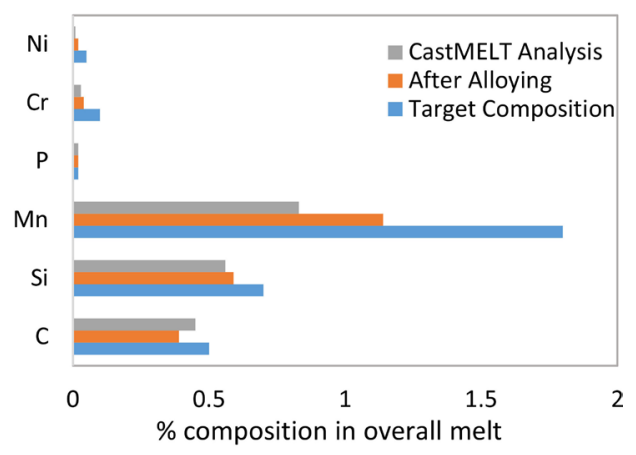

(f)

Figure 11. Comparison between after alloy (real time SMS operation), model (CastMELT simulation engine) and target chemical composition of four melting operation in foundry B for six (6) melts.

98.85\%. This did not only validate the correctness of the model and the simulation engine developed but also, show its suitability for an improved outcome for the steelmaking shop using induction furnace. Foundry B could achieve final alloy composition before casting with limits within the target composition since it has a better scrap and operation control in the use of lower production tonnage tested and known scrap when compared with foundry A.

Charge calculation assessment of the model for foundry-A melting test shows R-squared, Standard Error, Pearson correlation and Significance value of (0.921, $0.021,0.908,0.09)$ for Carbon prediction, $(0.921,0.021,0.96,0.04)$ for Silicon prediction, $(0.814,0.0662,0.815,0.186)$ for Manganese Prediction, and (0.792, 
$0.001,0.89,0.11)$ for Chromium Prediction respectively. The drawback in the correlation and confidence measurement was however due to the absence of a mill-scale record in the production record. The foundry practice of mill scale addition in foundry $\mathrm{A}$ is through trial-and-error. For comparison, the mill scale addition was computed using a reverse mass balance and stoichiometry calculations to give a rough estimate of what is to be charged into the melt during production.

\subsection{Techno-Economic Analysis}

With respect to materials savings especially for ferro additives, the simulation of the developed model using the same operations data produced was able to predict after alloy melt composition which falls within the range of the target composition but closer to the lower boundary value of the target chemistry for each element (supplementary material 3 and 4). The results using the model could be used to predict the optimized amount of ferroalloy addition which could bring large savings on material cost during melt treatment to achieve the target composition.

A comparison made between the ferroalloy addition in the real-time production at both foundries where the test is being carried out to validate this model and the ferroalloy predicted for using the simulation engine (CastMELT). Table 1 and Table 2 show the outcome of material savings which is achievable when both results are compared. The model is designed to estimate an optimized amount of material added to the melt which is just enough to make it achieve the minimum lower boundary limit of the target composition. This is shown in Figure 10 and Figure 11, which the CastMELT after alloy results is farther away from the target the composition when compared with the after alloy result of the steel melting shop for the focused elements (carbon, silicon, manganese, and chromium).

For a total of 41 tons of low-alloy medium carbon steel produced in foundry A and 9 tons of high-alloy cast iron melt produced during the performance assessment of the model, an average of $0.98 \%-2.5 \%$ savings is achieved using the developed model to achieve target melt composition when compared with the material utilization in both foundries that were used for the validation. For techno-economic evaluation based on 1 USD to NGN 360, a possible savings of $350-380 \$ /$ ton and $75-81.4 \$ /$ ton of melt produced is achieved on ferroalloy addition for foundry $\mathrm{A}$ and $\mathrm{B}$, respectively. This results in an annual savings of $100,000 \$ / y$ in foundry-A and 20,000 $\$ / y$ foundry-B for ferroalloy materials charge.

\section{Conclusions}

In this study, a numerical model for charge balancing and melt optimization has been developed and validated using real-time experimental investigations at a high-alloy cast iron and low-alloy medium steel carbon foundries. Process algo- 
rithm which combines a charge optimization and make-to-order approach for induction furnace melting of scrap was developed and used as the basis for developing a numerical model to establish the algorithm. The numerical model was developed using the system-level methodology for plant systems, GaussSeidel method of successive displacement, boundary value problem and partial differential equations to analyse the overall architecture of materials charge and melt optimization in the induction furnace. A simulation engine was also developed in Java IDE with a MySQL database server script to run the model.

The performance of this model was assessed in two separate foundries for high-alloy cast iron and low-allow medium carbon steel production with a real-time production data analysis. The validation investigates the utilization of the model for charge calculation and material balancing, melt adjustment, and optimization of ferro additives. The results using the simulation engine (CastMELT) indicates a correlation coefficient of $81 \%$ for the low-alloy steel (foundry-A) and

Table 1. Economic results of materials charge for a total of 41 tons of low-alloy steel melt produced in Foundry A.

\begin{tabular}{|c|c|c|c|c|c|c|c|c|}
\hline \multicolumn{9}{|c|}{ CastMELT Material Optimization Savings-Foundry $A^{*}$} \\
\hline & & & $\mathrm{FeSi}$ & HCFeMn & Mill Scale & SiMn & Total Charge & Total Savings (N) \\
\hline \multirow[t]{2}{*}{1} & $1,170,346-\mathrm{NFL}$ & 9860 & * & * & 190 & 149 & 10,199 & \\
\hline & CastMELT & 9860 & 46 & 77 & 101.36 & * & 10,136 & 20,430 \\
\hline $\begin{array}{c}\text { Material } \\
\text { Savings/Loss }\end{array}$ & & & -46 & -77 & 37 & 149 & & \\
\hline $\begin{array}{c}\text { Savings on } \\
\text { Production Cost (N) }\end{array}$ & & & $-18,216$ & $-27,720$ & 1998 & 64,368 & & \\
\hline \multirow[t]{2}{*}{2} & $2,170,340$ & 9170 & * & * & 200 & 100 & 9470 & \\
\hline & CastMELT & 9170 & 19 & 32.5 & 32 & * & 9253.5 & 33,048 \\
\hline $\begin{array}{c}\text { Material } \\
\text { Savings/Loss }\end{array}$ & & & -19 & -32.5 & 168 & 100 & & \\
\hline $\begin{array}{c}\text { Savings on } \\
\text { Production Cost }(\mathrm{N})\end{array}$ & & & -7524 & $-11,700$ & 9072 & 43200 & & \\
\hline \multirow[t]{2}{*}{3} & $2,170,342$ & 11400 & * & * & 220 & 205 & 11825 & \\
\hline & CastMELT & 11400 & 36 & 31 & 79 & * & 11546 & 70,758 \\
\hline $\begin{array}{c}\text { Material } \\
\text { Savings/Loss }\end{array}$ & & & -36 & -31 & 141 & 205 & 4.8 & \\
\hline $\begin{array}{c}\text { Savings on } \\
\text { Production Cost (N) }\end{array}$ & & & 14,256 & 11,160 & 7614 & 88,560 & & \\
\hline \multirow[t]{2}{*}{4} & $2,170,343$ & 9600 & * & * & 160 & 120 & 9880 & \\
\hline & CastMELT & 9600 & 42 & 70 & 112 & * & 9824 & 12,600 \\
\hline $\begin{array}{c}\text { Material } \\
\text { Savings/Loss }\end{array}$ & & & -42 & -70 & 48 & 120 & & \\
\hline $\begin{array}{c}\text { Savings on } \\
\text { Production Cost }(\mathrm{N})\end{array}$ & & & 16,632 & $-25,200$ & 2592 & 51,840 & & \\
\hline
\end{tabular}

${ }^{\star}$ Cost per ton-FeSi: \$1100, SiMn: \$1200, MCFeMn: \$1000, Mill Scale: \$150, Graphite: \$600. 
Table 2. Economic results of materials charge for a total of 9 tons of high-alloy cast iron melt produced in Foundry B.

\begin{tabular}{|c|c|c|c|c|c|c|c|c|c|c|c|c|}
\hline \multicolumn{13}{|c|}{ CastMELT Material Optimization Savings ${ }^{* *}$} \\
\hline & & & $\mathrm{FeSi}$ & Graphite & $\begin{array}{c}\text { HC } \\
\text { FeMn }\end{array}$ & $\begin{array}{c}\text { Mc } \\
\text { FeMn }\end{array}$ & $\begin{array}{l}\mathrm{HC} \\
\mathrm{FeCr}\end{array}$ & & & & Mins & $\begin{array}{l}\text { Total } \\
\text { Savings }\end{array}$ \\
\hline 1 & $\begin{array}{c}105171212 \\
(\mathrm{NFL})\end{array}$ & 1605 & 3 & * & 3 & 25 & * & 1636 & 1508 & 350 & 175 & \\
\hline & CastMELT & 1605 & 0.88 & & & 14.206 & & 1620 & 1508 & 350 & 152 & \\
\hline $\begin{array}{l}\text { Material } \\
\text { Savings }\end{array}$ & & & 2.12 & & 3 & 10.794 & & 16 & & & & 6415.4 \\
\hline $\begin{array}{l}\text { Savings on } \\
\text { Production } \\
\text { Cost }(\mathrm{N})\end{array}$ & & & 1007 & & 1134 & 4274 & & & & & & \\
\hline 2 & $\begin{array}{c}105171211 \\
(\mathrm{NFL})\end{array}$ & 1980 & * & * & 10 & 80 & * & 2070 & 1508 & $\begin{array}{c}300- \\
350\end{array}$ & 260 & \\
\hline & CastMELT & 1980 & * & * & * & 77 & * & 2057 & 1508 & $\begin{array}{c}300- \\
350\end{array}$ & 227 & 4806 \\
\hline $\begin{array}{l}\text { Material } \\
\text { Savings }\end{array}$ & & & & & 10 & 3 & & 13 & & & & \\
\hline $\begin{array}{l}\text { Savings on } \\
\text { Production } \\
\text { Cost }(\mathrm{N})\end{array}$ & & & & & 3780 & 1026 & & & & & & \\
\hline 3 & $\begin{array}{c}10517611 \\
(\mathrm{NFL})\end{array}$ & 802 & 7.5 & * & 10.5 & * & * & 820 & 1580 & 150 & 200 & \\
\hline & CastMELT & 802 & 6 & * & * & 7.2 & * & 815.2 & 1580 & 150 & 185 & \\
\hline $\begin{array}{l}\text { Material } \\
\text { Savings }\end{array}$ & & & 1.5 & & 10.5 & -7.2 & & 4.8 & & & & 1611 \\
\hline $\begin{array}{l}\text { Savings on } \\
\text { Production } \\
\text { Cost }(\mathrm{N})\end{array}$ & & & 594 & & & 1017 & & & & & & \\
\hline 4 & $\begin{array}{c}8517611 \\
(\mathrm{NFL})\end{array}$ & 1000 & 5 & * & * & * & 10 & 1015 & 1520 & 300 & 120 & \\
\hline & CastMELT & 1000 & 5.34 & * & * & * & * & 1005.34 & 1520 & 300 & 111.69 & 3286 \\
\hline $\begin{array}{l}\text { Material } \\
\text { Savings }\end{array}$ & & & -0.34 & & & 10 & & & & & & \\
\hline $\begin{array}{l}\text { Savings on } \\
\text { Production } \\
\text { Cost }(\mathrm{N})\end{array}$ & & & -134.4 & & & 3420 & & & & & & \\
\hline 5 & $\begin{array}{c}185171221 \\
(\mathrm{NFL})\end{array}$ & 2875 & 15 & * & * & 50 & * & 2940 & 1575 & 450 & 230 & \\
\hline & CastMELT & 2875 & 17.8 & * & * & 18 & * & 2911 & 1575 & 450 & 220 & \\
\hline $\begin{array}{l}\text { Material } \\
\text { Savings }\end{array}$ & & & -2.8 & & & 32 & & & & & & \\
\hline $\begin{array}{l}\text { Savings on } \\
\text { Production } \\
\text { Cost }(\mathrm{N})\end{array}$ & & & 1108 & & & 10944 & & & & & & 9886 \\
\hline 6 & $\begin{array}{c}95171221 \\
(\mathrm{NFL})\end{array}$ & 2050 & 14 & * & 30 & * & * & 2094 & 1580 & $\begin{array}{c}300- \\
350\end{array}$ & 237 & \\
\hline
\end{tabular}




\section{Continued}

\begin{tabular}{|c|c|c|c|c|c|c|c|c|c|c|c|c|}
\hline & CastMELT & 2050 & 15.4 & 7 & 19 & * & * & 2091 & 1580 & $\begin{array}{c}300- \\
350\end{array}$ & 237 & \\
\hline $\begin{array}{l}\text { Material } \\
\text { Savings }\end{array}$ & & & -1.4 & -7 & 11 & & & & & & & \\
\hline Savings on & & & & & & & & & & & & \\
\hline $\begin{array}{c}\text { Production } \\
\text { Cost }(\mathrm{N})\end{array}$ & & & 554.4 & 1512 & 4158 & & & & & & & 3301 \\
\hline
\end{tabular}

${ }^{* *}$ Cost per ton-FeSi: \$1100, HCFeMn: \$1050, MCFeMn: \$1000, HCFeCr: \$950, Graphite: \$600.

95.7\% for the high-alloy cast iron (foundry-B). Based on the elemental prediction, Pearson's correlation for silicon and carbon results in $96 \%$ and $90.7 \%$ respectively for foundry-A melting practice. Carbon and manganese had the highest correlation at $99 \%$ each for charge calculation and material balance in foundry-B based on the melting practice and approach. A convergence of $91.05 \%$ and $97.87 \%$ for final bath alloy prediction was obtained in foundries A and B, respectively, when compared with the final target composition which is being worked towards in both foundries.

Using the make-to-order the model achieves optimum addition of ferroalloy by bringing the element that is deficient in the melt within the range that is aimed for the final melt. This is done by a selective target of specific elements and solving for the lower boundary value problem of the standard melt composition. The model achieves convergence of 97.87 for final alloy melt simulation for foundry A compared with $91.05 \%$ convergence of the melting shop and $97.87 \%$ convergence for final melt alloy simulation compared with $97.82 \%$ in foundry B for overall melting correlation. Techno-economic evaluation of the use of the model in place of the current practice at the test foundries showed that $0.98 \%-0.25 \%$ ferroalloy saving per ton of melt is possible using the model. This brings about an annual production cost savings of 100,000 \$/y in foundry A and $20,000 \$ / y$ in foundry B on the use of different ferroalloy materials.

\section{Conflicts of Interest}

The authors declare no conflicts of interest regarding the publication of this paper.

\section{References}

[1] DeGarmo, E.P., Black, J.T., Kohser, R.A. and Klamecki, B.E. (1997) Materials and Process in Manufacturing. Prentice Hall, Upper Saddle River.

[2] Beeley, P. (2001) Foundry Technology. Elsevier, Amsterdam.

[3] Czapla, M., Karbowniczek, M. and Michaliszyn, A. (2008) The Optimisation of Electric Energy Consumption in the Electric Arc Furnace. Archives of Metallurgy and Materials, 53, 559-565.

[4] Deo, B. and Boom, R. (1993) Fundamentals of Steelmaking Metallurgy. Prentice-Hall, Upper Saddle River.

[5] Matsuura, H., Manning, C.P., Fortes, R.A.F.O. and Fruehan, R.J. (2008) Develop- 
ment of a Decarburization and Slag Formation Model for the Electric Arc Furnace. ISIJ International, 48, 1197-1205. https://doi.org/10.2355/isijinternational.48.1197

[6] Seidu, S.O. and Onigbajumo, A. (2015) Development of Charge Calculation Program for Target Steel in Induction Furnace. Leonardo Electronic Journal of Practices and Technologies, 14, 81-97.

[7] Seidu, S.O. and Onigbajumo, A. (2016) Effect of Casting Wall Thickness and Pouring Temperature on Residual Stress Build up in Aluminium 6063 Casting. Leonardo Journal of Sciences, 29, 148-160.

[8] Ekmekçi, İ., Yetisken, Y. and Çamdali, Ü. (2007) Mass Balance Modeling for Electric Arc Furnace and Ladle Furnace System in Steelmaking Facility in Turkey. Journal of Iron and Steel Research International, 14, 1-6. https://doi.org/10.1016/S1006-706X(07)60064-8

[9] Yellishetty, M., Ranjith, P.G. and Tharumarajah, A. (2010) Iron Ore and Steel Production Trends and Material Flows in the World: Is This Really Sustainable? Resources, Conservation and Recycling, 54, 1084-1094.

https://doi.org/10.1016/j.resconrec.2010.03.003

[10] Abubakre, O.K., Muriana, R.A., et al. (2009) Mathematical Model for Optimizing Charge and Heel Levels in Steel Remelting Induction Furnace for Foundry Shop. Journal of Minerals \& Materials Characterization \& Engineering, 8, 417-425. https://doi.org/10.4236/jmmce.2009.86037

[11] Mills, K. (2011) The Estimation of Slag Properties.

[12] Nyssen, P., Marique, C., Prüm, C., Bintner, P. and Savini, L. (1999) A New Metallurgical Model for the Control of EAF Operations. Proceedings of the 6 th European Electric Steelmaking Conference, Düsseldorf, 13-15.

[13] Sandberg, E. (2005) Energy and Scrap Optimisation of Electric Arc Furnaces by Statistical Analysis of Process Data.

[14] Sandberg, E., Lennox, B. and Undvall, P. (2004) Multivariate Prediction of End Conditions for Electric Arc Furnaces. Proceedings of the 2nd International Confence on Process Development in Iron and Steelmaking, Luleå, 6-9.

[15] Yetişken, Y., Çamdalı, Ü. and Ekmekci, I. (2010) Optimum Charging Materials for Electric Arc Furnace (eaf) and Ladle Furnace (lf) System: A Sample Case.

[16] Bara, N. (1988) Review Paper on Numerical Analysis of Induction Furnace. International Journal of Latest Trends in Engineering and Technology, 3, 549-557.

[17] Wei, J.-H. and Zhu, D.-P. (2002) Mathematical Modeling of the Argon-Oxygen Decarburization Refining Process of Stainless Steel: Part I. Mathematical Model of the Process. Metallurgical and Materials Transactions B, 33, 111-119. https://doi.org/10.1007/s11663-002-0091-5

[18] Yetişken, Y., Ekmekçi, İ. and Çamdalı, Ü. (2013) Optimum Charging Materials for Electric Arc Furnace (eaf) and Ladle Furnace (lf) System by Using Cost and Exergy Analysis.

[19] Liu, M.S., Choi, C.K. and Leung, C.W. (2001) Startup Analysis of Oil-Fired Furnace: The Smoothing Monte Carlo Model Approach. Heat and Mass Transfer, 37, 449-457. https://doi.org/10.1007/PL00013296

[20] Bhamare, L.P., Shejwal, N.V., Patil, P.S. and Jadhav, P.C. (2015) Furnace Monitoring and Billet Cutting System.

[21] Li, X., Guo, S., Liu, Y., Du, B. and Wang, L. (2017) A Production Planning Model for Make-to-Order Foundry Flow Shop with Capacity Constraint. Mathematical Problems in Engineering, 2017, Article ID: 6315613. 
https://doi.org/10.1155/2017/6315613

[22] Bermúdez, A., Reales, C., Rodriguez, R. and Salgado, P. (2010) Numerical Analysis of a Finite-Element Method for the Axisymmetric Eddy Current Model of an Induction Furnace. IMA Journal of Numerical Analysis, 30, 654-676.

https://doi.org/10.1093/imanum/drn063

[23] Dutta, S.K., Lele, A.B. and Pancholi, N.K. (2004) Studies on Direct Reduced Iron Melting in Induction Furnace. Transactions of the Indian Institute of Metals, 57, 467-473.

[24] Alshaikhli, A.K.M., Al-khairo, M.M., Jahanger, H.K. and Faris, F.H. (2014) Design and Construction of the Coreless Induction Furnace. International Journal of Scientific \& Engineering Research, 5, 697-705.

[25] Thakur, P.K., Prakash, S.K., Muralidharan, S.K.G., Bahl, V. and Das, S.S. (2014) A Review on Efficient Energy Optimization in Reheating Furnaces. Proceedings of 16th IRF International Conference, 14 December 2014, 43-49.

[26] Gandhewar, V.R., Bansod, S.V. and Borade, A.B. (2011) Induction Furnace: A Review. International Journal of Engineering and Technology, 3, 277-284. 


\section{Supplementary Materials}

\section{Supplementary Material 1. Operational Data for Cast Iron Production in Factory A}

\begin{tabular}{|c|c|c|c|c|c|c|c|c|c|c|c|c|c|}
\hline $\begin{array}{c}\text { Prod } \\
\text { No. }\end{array}$ & $\begin{array}{c}\text { Batch } \\
\text { No. }\end{array}$ & $\begin{array}{l}\text { Total } \\
\text { Melting } \\
\text { Time }\end{array}$ & $\begin{array}{l}\text { Starting } \\
\text { Time }\end{array}$ & $\begin{array}{l}\text { End } \\
\text { Time }\end{array}$ & $\begin{array}{c}\text { Light } \\
\text { Scrap } \\
(\mathrm{kg})\end{array}$ & $\begin{array}{c}\text { Heavy } \\
\text { Scrap } \\
(\mathrm{kg})\end{array}$ & $\begin{array}{c}\text { Bundle/Reba } \\
\text { r (kg) }\end{array}$ & $\begin{array}{c}\text { Total } \\
\text { Scrap } \\
(\mathrm{kg})\end{array}$ & $\begin{array}{c}\text { Power } \\
\text { consumption } \\
(\mathrm{kWh})\end{array}$ & $\begin{array}{l}\text { Tap to } \\
\text { Tap } \\
\text { Time } \\
\text { (mins) }\end{array}$ & $\begin{array}{l}\text { Tapping } \\
\text { Temp } \\
\left({ }^{\circ} \mathrm{C}\right)\end{array}$ & $\begin{array}{l}\text { Wt. of } \\
\text { Alloy } \\
(\text { SiMn })\end{array}$ & $\begin{array}{c}\text { Total } \\
\text { Wt. of } \\
\text { Billet } \\
(\mathrm{kg})\end{array}$ \\
\hline 1 & $1,170,345$ & 102 & 7:18 PM & $10: 50 \mathrm{PM}$ & 6200 & 2270 & nil & 8470 & 9768.1 & 102 & 1886 & 122 & 8210 \\
\hline 2 & $1,170,346$ & 110 & 11:05 PM & 2:02 AM & 8115 & nil & 1745 & 9860 & $10,620.5$ & 110 & 1793 & 149 & 5660 \\
\hline 3 & $2,170,341$ & 97 & 10:50 PM & 1:00 AM & 4150 & nil & 4150 & 8300 & 8252.9 & 90 & 1804 & 140 & 8100 \\
\hline 4 & $2,170,342$ & 115 & $1: 10 \mathrm{PM}$ & 4:07 PM & 5825 & 2080 & 2775 & 11,400 & $14,057.7$ & 115 & 1800 & 85 & 11,260 \\
\hline 5 & $2,170,343$ & 99 & 7:34 PM & 9:40 PM & 4815 & 2755 & 2030 & 9600 & 8741.4 & 99 & 1782 & 120 & 9400 \\
\hline 6 & $2,170,345$ & 105 & $12: 12 \mathrm{PM}$ & $2: 25 \mathrm{PM}$ & 6850 & nil & 2850 & 9700 & 8950 & 105 & 1799 & 130 & 9455 \\
\hline
\end{tabular}

F1 (50\%): $\mathrm{C}=0.377, \mathrm{Si}=0.0727, \mathrm{Mn}=0.095, \mathrm{~S}=0.0248, \mathrm{Cr}=0.127, \mathrm{Mo}=0.0160 \mathrm{Ni}=0.0748, \mathrm{Cu}=0.178, \mathrm{Fe}=98.9, \mathrm{CEQ}=0.439$

$1 \quad \mathrm{BA}(80 \%): \mathrm{C}=0.396, \mathrm{Si}=0.0590, \mathrm{Mn}=0.112, \mathrm{~S}=0.0368, \mathrm{Cr}=0.156, \mathrm{Mo}=0.0171 \mathrm{Ni}=0.0835, \mathrm{Cu}=0.181, \mathrm{Fe}=98.8, \mathrm{CEQ}=0.467$ AA: $\mathrm{C}=0.178, \mathrm{Si}=0.324, \mathrm{Mn}=0.600, \mathrm{~S}=0.0366, \mathrm{Cr}=0.148, \mathrm{Mo}=0.0175 \mathrm{Ni}=0.0791, \mathrm{Cu}=0.175, \mathrm{Fe}=98.3, \mathrm{CEQ}=0.329$ $\mathrm{F} 1(50 \%): \mathrm{C}=0.326, \mathrm{Si}=0.285, \mathrm{Mn}=0.374, \mathrm{~S}=0.0444, \mathrm{Cr}=0.176, \mathrm{Mo}=0.0182, \mathrm{Ni}=0.0725, \mathrm{Cu}=0.161, \mathrm{Fe}=98.4, \mathrm{CEQ}=0.443$

$2 \mathrm{BA}(80 \%): \mathrm{C}=0.267, \mathrm{Si}=0.208, \mathrm{Mn}=0.35, \mathrm{~S}=0.0419, \mathrm{Cr}=0.160, \mathrm{Mo}=0.0163, \mathrm{Ni}=0.0671, \mathrm{Cu}=0.148, \mathrm{Fe}=98.6, \mathrm{CEQ}=0.375$ AA: $\mathrm{C}=0.206, \mathrm{Si}=0.451, \mathrm{Mn}=0.787, \mathrm{~S}=0.0421, \mathrm{Cr}=0.165, \mathrm{Mo}=0.0160 \mathrm{Ni}=0.066, \mathrm{Cu}=0.149, \mathrm{Fe}=98.7, \mathrm{CEQ}=0.392$ F1 (50\%): $\mathrm{C}=0.211, \mathrm{Si}=0.0481, \mathrm{Mn}=0.0843, \mathrm{~S}=0.0422, \mathrm{Cr}=0.153, \mathrm{Mo}=0.0180 \mathrm{Ni}=0.103 \mathrm{Cu}=0.169, \mathrm{Fe}=99.0, \mathrm{CEQ}=0.278$

\section{No sample}

AA: $\mathrm{C}=0.184, \mathrm{Si}=0.250, \mathrm{Mn}=0.515, \mathrm{~S}=0.0382, \mathrm{Cr}=0.186, \mathrm{Mo}=0.0154, \mathrm{Ni}=0.082, \mathrm{Cu}=0.149, \mathrm{Fe}=98.9, \mathrm{CEQ}=0.331$ F1 (50\%): $\mathrm{C}=0.164, \mathrm{Si}=0.0453, \mathrm{Mn}=0.0971, \mathrm{~S}=0.0426, \mathrm{Cr}=0.131, \mathrm{Mo}=0.0175, \mathrm{Ni}=0.0703, \mathrm{Cu}=0.175, \mathrm{Fe}=99.1, \mathrm{CEQ}=0.225$ BA (80\%): $\mathrm{C}=0.249, \mathrm{Si}=0.131, \mathrm{Mn}=0.407, \mathrm{~S}=0.0421, \mathrm{Cr}=0.126, \mathrm{Mo}=0.0179, \mathrm{Ni}=0.0683, \mathrm{Cu}=0.169, \mathrm{Fe}=98.8, \mathrm{CEQ}=0.261$ AA: $\mathrm{C}=0.206, \mathrm{Si}=0.330, \mathrm{Mn}=0.922, \mathrm{~S}=0.0352, \mathrm{Cr}=0.144, \mathrm{Mo}=0.0171, \mathrm{Ni}=0.0612, \mathrm{Cu}=0.142, \mathrm{Fe}=99.0, \mathrm{CEQ}=0.392$ F1 (50\%): $\mathrm{C}=0.322, \mathrm{Si}=0.0515, \mathrm{Mn}=0.0842, \mathrm{~S}=0.0287, \mathrm{Cr}=0.0926, \mathrm{Mo}=0.0177, \mathrm{Ni}=0.0665, \mathrm{Cu}=0.155, \mathrm{Fe}=99.1, \mathrm{CEQ}=0.372$ $\mathrm{BA}(80 \%): \mathrm{C}=0.250, \mathrm{Si}=0.0411, \mathrm{Mn}=0.0999, \mathrm{~S}=0.0361, \mathrm{Cr}=0.107, \mathrm{Mo}=0.0202, \mathrm{Ni}=0.0665, \mathrm{Cu}=0.150, \mathrm{Fe}=99.1, \mathrm{CEQ}=0.301$ AA: $\mathrm{C}=0.220, \mathrm{Si}=0.321, \mathrm{Mn}=0.971, \mathrm{~S}=0.0372, \mathrm{Cr}=0.121, \mathrm{Mo}=0.0191, \mathrm{Ni}=0.0642, \mathrm{Cu}=0.143, \mathrm{Fe}=98.8, \mathrm{CEQ}=0.422$ $\mathrm{F} 1(50 \%): \mathrm{C}=0.110, \mathrm{Si}=0.0284, \mathrm{Mn}=0.0715, \mathrm{~S}=0.0367, \mathrm{Cr}=0.0879, \mathrm{Mo}=0.0108, \mathrm{Ni}=0.0588, \mathrm{Cu}=0.155, \mathrm{Fe}=99.3, \mathrm{CEQ}=0.157$ 6 AA: $\mathrm{C}=0.191, \mathrm{Si}=0.347, \mathrm{Mn}=0.660, \mathrm{~S}=0.0392, \mathrm{Cr}=0.121, \mathrm{Mo}=0.0124, \mathrm{Ni}=0.0570, \mathrm{Cu}=0.149, \mathrm{Fe}=98.9, \mathrm{CEQ}=0.331$ 
Supplementary Material 2. Operational Data for Cast Iron Production in Factory B

\begin{tabular}{|c|c|c|c|c|c|c|c|c|c|c|c|c|c|}
\hline \multirow{2}{*}{$\begin{array}{c}\text { Melt } \\
\text { Sample \& } \\
\text { Date }\end{array}$} & \multirow{2}{*}{ Heat No } & \multirow{2}{*}{ Cast Prod. } & \multicolumn{2}{|c|}{ Scrap Mix (Kg) } & \multicolumn{4}{|c|}{ Alloy/Additive (Kg) } & \multirow{2}{*}{$\begin{array}{c}\begin{array}{c}\text { Total } \\
\text { Charge }\end{array} \\
(\mathrm{kg})\end{array}$} & \multirow{2}{*}{$\begin{array}{c}\text { Tap } \\
\text { Temp } \\
\left({ }^{\circ} \mathrm{C}\right)\end{array}$} & \multirow{2}{*}{$\begin{array}{c}\text { Fur. } \\
\text { CAP. } \\
(\mathrm{T})\end{array}$} & \multirow{2}{*}{$\begin{array}{c}\text { Pwr. Rat. } \\
\text { (KW) }\end{array}$} & \multirow{2}{*}{$\begin{array}{l}\text { Cyc. } \\
\text { Time }\end{array}$} \\
\hline & & & $\begin{array}{l}\text { Steel/Cast } \\
\text { Iron }\end{array}$ & Fdr. Returns & MCFeMn & HCFeMn & $\mathrm{HCFeCr}$ & $\mathrm{FeSi}$ & & & & & \\
\hline $04 / 05 / 2017$ & 105171212 & NFMN128C & 850 & $\begin{array}{c}400(18 \mathrm{Mn})+ \\
200(14 \mathrm{Mn})\end{array}$ & $80 / 25$ & $50 / 3$ & 25 & $0 / 3$ & 1633 & 1508 & 2 & 350 & 152 \\
\hline $\begin{array}{l}\text { Chemical } \\
\text { Analysis }\end{array}$ & $\mathrm{C}$ & SI & $\mathrm{MN}$ & NI & $\mathrm{CR}$ & $\mathbf{P}$ & & & & & & & \\
\hline $\begin{array}{l}\text { Actual } \\
\text { Melt }\end{array}$ & 1.11 & 0.64 & 11.98 & 0.06 & 2.64 & 0.03 & & & & & & & \\
\hline $1^{\text {st }}$ Spark & 1.11 & 0.78 & 12.85 & 0.06 & 2.64 & 0.03 & & & & & & & \\
\hline AIM & $0.9-1.2$ & $0.6-0.8$ & $12.0-13.0$ & $0.5 \mathrm{Max}$ & $1.5-2.0$ & $0.07 \mathrm{Max}$ & & & & & & & \\
\hline $04 / 05 / 2017$ & 105171211 & NFMN-18 & 850 & 850 & 10 & $240 / 80$ & 30 -Oct & & 2070 & 1508 & 2 & $300-350$ & 235 \\
\hline $\begin{array}{l}\text { Chemical } \\
\text { Analysis }\end{array}$ & $\mathrm{C}$ & SI & MN & NI & $\mathrm{CR}$ & $\mathbf{P}$ & & & & & & & \\
\hline $\begin{array}{l}\text { Actual } \\
\text { Melt }\end{array}$ & 1.07 & 0.86 & 14.38 & 0.09 & 1.54 & 0.05 & & & & & & & \\
\hline $1^{\text {st }}$ Spark & 1.12 & 0.84 & 16.81 & 0.04 & 1.75 & 0.04 & & & & & & & \\
\hline AIM & $1.0-1.2$ & $0.6-0.8$ & $16.0-18.0$ & $0.5 \mathrm{Max}$ & $1-2.5$ & $0.07 \mathrm{Max}$ & & & & & & & \\
\hline $04 / 05 / 2017$ & 10517611 & NF11055-O & 700 & & $5 / 8$ & $7-\mathrm{Oct}$ & 15 & 75 & 820 & 1580 & 1 & $150-200$ & 98 \\
\hline $\begin{array}{l}\text { Chemical } \\
\text { Analysis }\end{array}$ & $\mathrm{C}$ & SI & $\mathrm{MN}$ & NI & $\mathrm{CR}$ & $\mathrm{P}$ & & & & & & & \\
\hline $\begin{array}{l}\text { Actual } \\
\text { Melt }\end{array}$ & 0.27 & 0.86 & 14.38 & 0.09 & 1.54 & 0.05 & & & & & & & \\
\hline $1^{\text {st }}$ Spark & 1.12 & 0.84 & 16.81 & 0.04 & 1.75 & 0.04 & & & & & & & \\
\hline AIM & $0.2-0.3$ & $0.6-1.0$ & $0.8-1.5$ & 0.05 & $6.0-8.0$ & 0.03 & & & & & & & \\
\hline $5 / 05 / 2017$ & 8517611 & NFMN128C & 800 & & $0 / 2$ & 180 & $20 / 10 /$ & & 1012 & 1520 & 1 & 300 & 112 \\
\hline $\begin{array}{l}\text { Chemical } \\
\text { Analysis }\end{array}$ & $\mathrm{C}$ & SI & $\mathrm{MN}$ & NI & $\mathrm{CR}$ & $\mathrm{P}$ & & & & & & & \\
\hline $\begin{array}{l}\text { Actual } \\
\text { Melt }\end{array}$ & 0.98 & 0.21 & 13.03 & 0.03 & 1.66 & 0.03 & & & & & & & \\
\hline $1^{\text {st }}$ Spark & 1.05 & 0.59 & 12.89 & 0.03 & 1.9 & 0.03 & & & & & & & \\
\hline AIM & $0.9-1.2$ & $0.6-0.8$ & $12.0-13.0$ & 0.5 & $1.5-2.0$ & 0.07 & & & & & & & \\
\hline $8 / 05 / 2017$ & 85171221 & BS3100AW2 & $2000 / 875 /$ & & $0 / 0 / 15$ & $0 /-/ 50$ & & & 2940 & 1575 & 2 & 450 & 250 \\
\hline $\begin{array}{l}\text { Chemical } \\
\text { Analysis }\end{array}$ & $\mathrm{C}$ & SI & $\mathrm{MN}$ & NI & $\mathrm{CR}$ & $\mathrm{P}$ & & & & & & & \\
\hline $\begin{array}{l}\text { Actual } \\
\text { Melt }\end{array}$ & 0.88 & 0.25 & 0.6 & 0.04 & 0.05 & 0.02 & & & & & & & \\
\hline $1^{\text {st }}$ Spark & 0.51 & 0.1 & 0.35 & 0.03 & 0.08 & 0.02 & & & & & & & \\
\hline $2^{\text {nd }}$ Spark & 0.49 & 0.47 & 1.6 & 0.03 & 0.08 & 0.02 & & & & & & & \\
\hline AIM & $0.4-0.5$ & $0.55-0.7$ & $0.8-1.2$ & 0.05 & 0.3 & 0.07 & & & & & & & \\
\hline 9/05/2017 & 95171221 & BS3100AW2 & 1900 & $0 / 150$ & $0 / 14$ & $0 / 30$ & & & 2094 & 1580 & 2 & $300-350$ & 215 \\
\hline
\end{tabular}




\section{Continued}

\begin{tabular}{|c|c|c|c|c|c|c|c|c|c|c|c|c|c|}
\hline $\begin{array}{l}\text { Chemical } \\
\text { Analysis }\end{array}$ & $\mathrm{C}$ & SI & $\mathrm{MN}$ & NI & CR & $\mathrm{P}$ & & & & & & & \\
\hline $\begin{array}{c}\text { Actual } \\
\text { Melt }\end{array}$ & 0.06 & 0.001 & 0.1 & 0.01 & 0.03 & 0.02 & & & & & & & \\
\hline $1^{\text {st }}$ Spark & 0.39 & 0.59 & 1.14 & 0.02 & 0.04 & 0.02 & & & & & & & \\
\hline AIM & $0.4-0.5$ & $0.55-0.7$ & $0.8-1.2$ & 0.05 & 0.3 & 0.07 & & & & & & & \\
\hline $9 / 05 / 2017$ & 9517611 & NF11055-O & 900 & & $05 / 6.5$ & $0 / 5$ & $0 / 4.5$ & 105 & 1026 & 1580 & 1 & $150-200$ & 260 \\
\hline $\begin{array}{l}\text { Chemical } \\
\text { Analysis }\end{array}$ & $\mathrm{C}$ & SI & $\mathrm{MN}$ & NI & CR & $\mathrm{P}$ & & & & & & & \\
\hline $\begin{array}{c}\text { Actual } \\
\text { Melt }\end{array}$ & 0.08 & 0.23 & 0.53 & 0.06 & 5.25 & 0.02 & & & & & & & \\
\hline AIM & $0.2-0.3$ & $0.6-1.0$ & $0.8-1.5$ & 0.05 & $6.0-8.0$ & 0.03 & & & & & & & \\
\hline
\end{tabular}

Supplementary Material 3. Comparison between Real Time Spectrometric Result in Foundry A and the Final Chemical Composition Output from CastMELT Simulation Engine

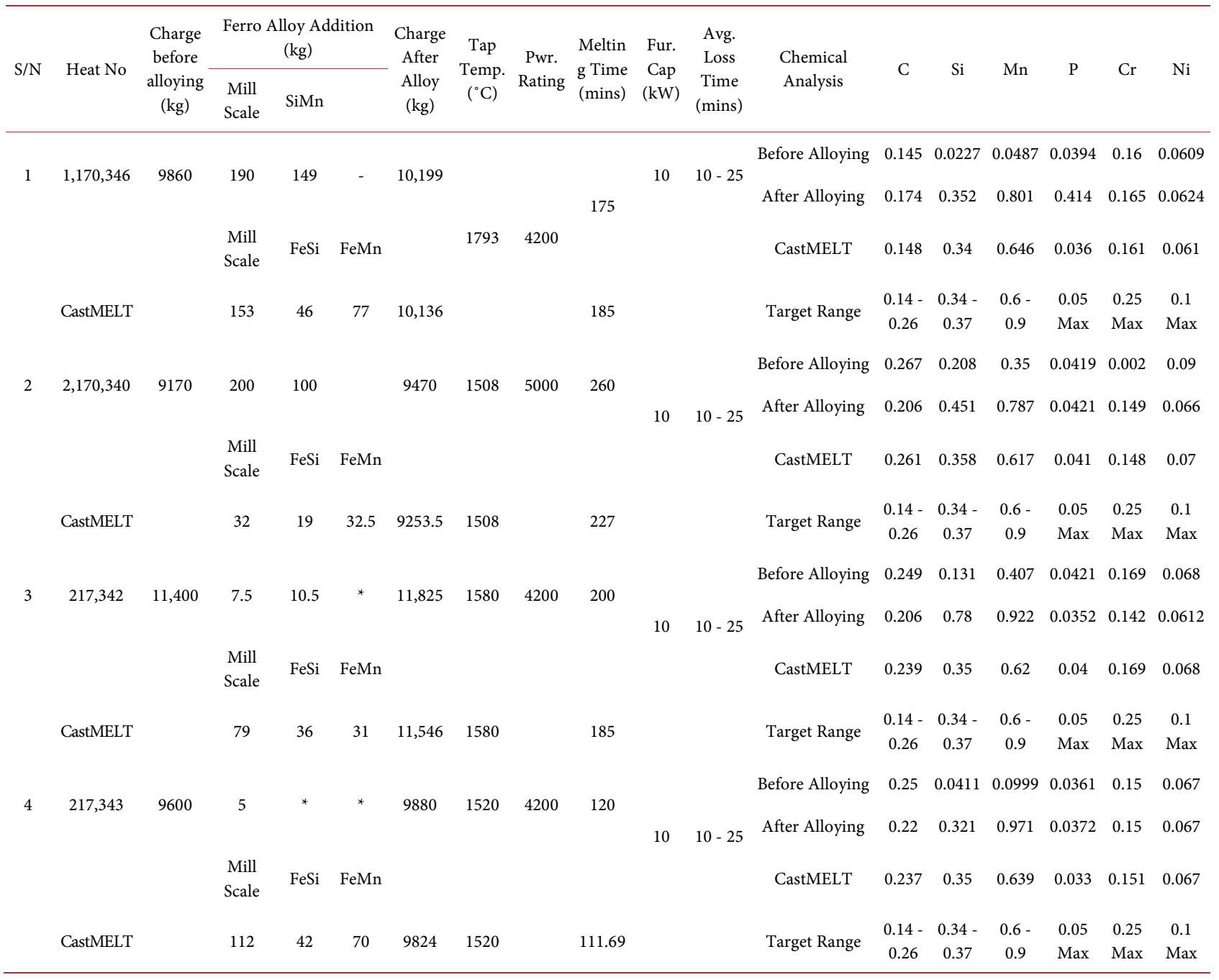


Supplementary Material 4. Comparison between Real Time Spectrometric Result in Foundry B and the Final Chemical Composition Output from CastMELT Simulation Engine

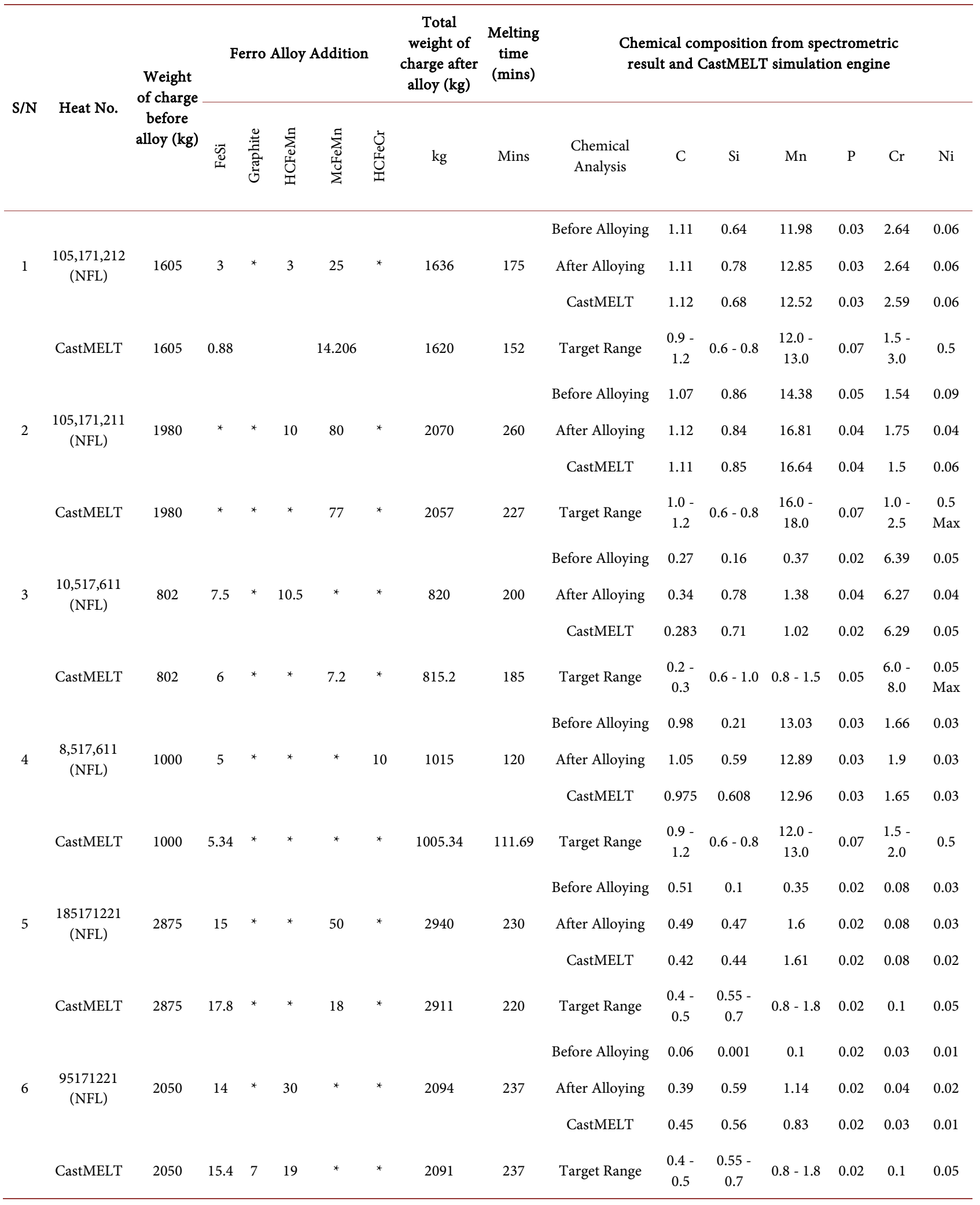

